\title{
Using Actor-Based Theories of Change to Conduct Robust Evaluation in Complex Settings
}

\author{
Andrew Koleros \\ Mathematica Policy Research \\ John Mayne
}

\begin{abstract}
The use of theories of change (ToCs) is a hallmark of sound evaluation practice. As interventions have become more complex, the development of ToCs that adequately unpack this complexity has become more challenging. Equally important is the development of evaluable ToCs, necessary for conducting robust theory-based evaluation approaches such as contribution analysis (CA). This article explores one approach to tackling these challenges through the use of nested actor-based ToCs using the case of an impact evaluation of a complex police-reform program in the Democratic Republic of Congo, describing how evaluable nested actor-based ToCs were built to structure the evaluation.
\end{abstract}

Keywords: actors, complexity, pathways, theories of change

Résumé : L’utilisation d'une théorie du changement fait partie des bonnes pratiques en évaluation. Compte tenu de la complexité croissante des interventions, l'élaboration de théories du changement reflétant cette complexité devient de plus en plus difficile. Parallèlement, la capacité d'utiliser ces modèles pour les évaluations axées sur la théorie, comme l'analyse de la contribution, est tout aussi importante. Cet article explore une approche visant à relever ces défis soit la théorie du changement imbriquée et fondée sur les acteurs avec, comme exemple illustrant la pertinence de cette approche, le cas de lévaluation des répercussions d'un programme complexe de réforme des corps policiers à la République démocratique du Congo.

Mots clés : acteurs, complexité, cheminements, théories du changement

A key aim of this special issue is to enhance the development, validation, and use of program theories in evaluation practice. The introductory chapter provides background on the development and use of program theories in the evaluation of different types of interventions. One issue evaluators currently face to the use of program theories in evaluation practice is the fact that many settings now involve complex interventions (Byrne, 2013; Copestake, 2014; Garcia \& Zazueta, 2015; Gerrits \& Verweij, 2015; Ramalingam, 2013; Ramalingam \& Jones, 2008),

Corresponding author: Andrew Koleros, Mathematica Policy Research, 955 Massachusetts Avenue, Suite 801, Cambridge, MA 02139; apkoleros@gmail.com

(C) 2019 Canadian Journal of Program Evaluation / La Revue canadienne d'évaluation de programme 33.3 (Special Issue / Numéro special), 292-315 doi: 10.3138/cjpe.52946 
interventions that contain some or all of the following characteristics (Befani, Barnett, \& Stern, 2014; Mayne, forthcoming):

- $\quad$ numerous types of activities undertaken;

- a number of partners delivering different aspects of the intervention;

- involvement of several layers of government;

- many external factors at play;

- a number of different actors involved in the intervention;

- feedback loops;

- $\quad$ emerging outcomes and uncertainty; and

- a multi-year timeframe.

Without unpacking this complexity through program theory, evaluators struggle to fully identify what is going on in an intervention, determine what aspects of it are working (or not), and understand whether interventions are playing a positive causal role in bringing about (expected) change.

A second issue that arises, especially in complex settings, is the need to ensure that program theories, or theories of change (ToCs), are "evaluable." As many have noted (James, 2011; Stein \& Valters, 2012; Valters, 2014; Vogel, 2012), theories of change in the literature are extremely varied, serving widely different purposes. What the evaluator needs is a ToC that is useful for evaluation purposes.

Despite the importance of these two issues within current evaluation practice, developing evaluable program theories of change that adequately take account of this complexity within interventions remains a challenge for many evaluators (Funnell \& Rogers, 2011; Rogers, 2008). In this article, we discuss the development and use of actor-based nested ToCs as one approach to addressing some of these challenges in order to articulate an evaluable ToC that both addresses complexity and allows for sound theory-based evaluation.

Our aims in this article are as follows:

1. to describe how actor-based theories of change can be used to unpack complexity;

2. to discuss how to ensure that these actor-based ToCs are evaluable theories of change; and

3. to reinforce the importance of evaluable theories of change as the basis of sound evaluation practice.

We first present our definitions of ToCs and discuss the usefulness in complex settings of having a set of nested ToCs to represent the intervention in a practical and evaluable way. In particular, we highlight how the use of actor-based ToCs can facilitate this process and serve as the basis for sound theory-based evaluation practice. We then briefly outline contribution analysis, one theory-based approach in evaluation that relies heavily on solid, well-structured ToCs. These ideas and approaches are then illustrated through a discussion of key aspects of the evaluation of the Security Sector Accountability and Police Reform (SSAPR) 
program (Palladium, 2016) in the Democratic Republic of Congo (DRC), which used actor-based ToCs to conduct a theory-based evaluation using contribution analysis. We conclude with reflections on strengthening the use of actor-based ToCs in evaluation practice.

\section{USING THEORIES OF CHANGE IN COMPLEX SETTINGS}

\section{Theories of change and nested theories of change}

As noted in the introduction to this Special Issue, program theories (theories of change) are a key tool in theory-based evaluations. But different terms are used in the literature. We will use the following terms: impact pathways describe causal pathways showing the linkages between the steps that go from activities to impact; a theory of change adds to an impact pathway by describing the causal assumptions behind the links in the pathway-what has to happen for the causal linkages to be realized (Mayne, 2015, p. 121). Thus theories of change comprise both a pathway of results as well as the causal link assumptions for each step in the causal sequence, explaining how the causal link is expected to happen. A theory of change sets out the impact story of the intervention, or part thereof. An important idea to keep in mind, especially when contemplating a complex intervention, is that there need not be only one representation of an intervention's theory of change (Mayne, 2015, 2018a, 2018b; Mayne \& Johnson, 2015).

We have listed the kinds of characteristics that can be found in complex interventions (see above). A detailed ToC for representing such interventions would be a very complicated model. Indeed, trying to capture such a complex intervention in a single ToC is neither realistic nor helpful. The result is often a "spaghetti" ToC of little use to anyone other than those who developed it. There is a need, rather, to unpack the complexity into more manageable forms. In discussing these complexity challenges, Mayne (2015) argues for the need for a high-level overview ToC to capture the big picture of the intervention and show the key pathways to impact but not the details, and nested ToCs to provide more detail on the specific pathways within the intervention. Mayne and Johnson (2015) provide some examples in the setting of agriculture research for development.

The actor-based theories of changes discussed in this article often provide a very useful way to unpack this complexity. Complex interventions typically aim to change the behaviour of a number of actor groups involved in the intervention with specific activities undertaken to influence these groups. In the example discussed below, the actor groups include the police, the media, parliamentarians, the public, and the justice system. Actor-based ToCs involve building a ToC for each group to represent how the intervention aims to influence the group and the results that are then expected. Actor-based ToCs often interact with each other to produce the desired overall impacts, but it is of interest to know the actor impact stories: the extent to and the manner in which the intervention has in practice worked to influence these actor groups. 


\section{Contribution analysis: One theory-based evaluation approach}

As noted, ToCs are used in many theory-based evaluation approaches, such as realist evaluation and contribution analysis. Contribution analysis (CA) (Mayne, $2001,2009,2011,2012 a$ ) is increasingly being used in evaluations of interventions in order to address the perennial challenge of "dealing with causality," particularly in complex systems where changes in outcomes are the result of a number of factors in addition to the intervention-that is, situations where there are several factors acting together to bring about change, with each factor being a contributory cause and none being sufficient on its own to bring about the desired change (Mayne, 2012a; see also Buckley, 2016; Buregeya, Brousselle, Nour, \& Loignon, 2017; Delahais \& Toulemonde, 2017; Downes, Novicki, \& Howard, 2018; Kane, Levine, Orians, \& Reinelt, 2017; Mayne, 2012b; Noltze, Gaisbauer, Schwedersky, \& Krapp, 2014; Terrapon-Pfaff, Gröne, Dienst, \& Ortiz, 2018; and Ton, 2017.

The aim is to make credible causal claims about the contribution an intervention is making to observed results. CA argues that if one can verify or confirm a theory of change with empirical evidence, ${ }^{1}$ then it is reasonable to conclude that the intervention in question has made a difference. This is based on the observation that a ToC is a model of the intervention as a contributory cause (Mayne, 2012a).

The general steps in CA are as follows (Mayne, 2011):

Step 1: Set out the cause-effect issue to be addressed.

Step 2: Develop the postulated theory of change for the intervention.

Step 3: Gather the existing evidence on the theory of change.

Step 4: Assemble and assess the contribution claim, and the challenges to it.

Step 5: Seek out additional evidence to verify the theory of change.

Step 6: Revise and strengthen the contribution claim.

ToCs are thus a key tool in CA. It is obvious, however, that the strength of a contribution claim is only as good as the ToC being used. A weak ToC can only lead to weak contribution claims. Strong, well-structured ToCs that can be evaluated will support credible contribution claims. In the SSAPR evaluation discussed below, we used criteria developed by Davies (2013) for "evaluable" theories of change, that is, theories of change that are useful for evaluative purposes, such as conducting CA. The need for evaluable ToCs is clear, but this can present the evaluator with significant challenges when the intervention already has developed a ToC that, while useful for some purposes, is not very evaluable. The use of actor-based nested ToCs can help overcome some of these challenges.

\section{USING ACTOR-BASED NESTED TOCS TO STRUCTURE THE IMPACT EVALUATION OF A COMPLEX PROGRAM}

\section{Background on the SSAPR program}

The Security Sector Accountability and Police Reform (SSAPR) program in the Democratic Republic of Congo (DRC) was a five-year program funded by the UK 
Department for International Development (DFID) from January 2010 to May 2015. The stated goal of SSAPR at program design was to assist the Government of the DRC in laying the foundations for the re-establishment of the rule of law by supporting the creation of accountable and service-oriented security and justice institutions able to improve safety, security, and access to justice for Congolese citizens. SSAPR contributed to this overall goal specifically through support to the police-reform process, as well as improving the capacity of communities to cooperate with police and demand effective policing.

The program comprised four independently managed components: Project Support to the Police, Control and Coordination of Security Sector, External Accountability, and Monitoring and Evaluation. The first three components were designed to target different Congolese actors and empower them to work together to improve the public sense of security in the program's three pilot provinces (Bas Congo, Western Kasai, and South Kivu) as well as at the national policy level. Activities involved stakeholders from all aspects of public administration, police, and civil society, including the Ministry of Interior and Security (MIS), the Congolese National Police (Police Nationale Congolaise, PNC), the General Inspection Audit (Inspection Générale de l'Administration, IGA), the Secretariat of the Poverty Reduction Strategy Paper (PRSP), Parliament, civil society, and the media, along with magistrates and Congolese researchers. The Monitoring and Evaluation component of the program was commissioned after program design and was responsible for conducting ongoing program monitoring throughout implementation as well as the final impact evaluation of the program.

\section{Introduction to the SSAPR impact evaluation}

The evaluation aimed to answer the following questions for policy makers, program planners, and other stakeholders:

- Did SSAPR interventions contribute to changes in police capacity and accountability, stakeholder empowerment and ownership, and sustainability over the intervention period? How did these changes occur?

- Did these changes contribute to more effective policing? How did this occur?

- $\quad$ Did more effective policing contribute to improved security for Congolese citizens?

- What were the key factors that contributed to these changes?

Based on these evaluation questions, the evaluation team opted for a quasiexperimental design nested within an overall theory-based evaluation approach using CA as the analytical approach to guide causal inference analysis. This design approach was selected for a number of reasons. First, the three pilot cities selected for the intervention were not selected at random but purposively selected based on a series of programmatic criteria, particularly the security situation in these sites. Thus, by definition, a selection bias existed in that these sites were chosen 
because they exhibited a relatively poor security situation compared with other sites in the country. As such, a pure experimental design approach was not an option. We therefore decided on a difference-in-difference (DiD) approach based on city-level matching, to estimate the extent to which there was a change in populationlevel outcomes in program intervention sites. Each of the three intervention cities was matched with a comparison city to serve as its counterfactual. Cities were matched in 2010 based on a range of factors using available data, including relative population size, ethnicity, conflict level, region, language, recent historical trends, and geographical proximity.

The DiD approach is particularly appropriate when only one causal factor is under investigation. In the case of SSAPR, however, many possible factors could have had an impact on an individual's perception of security (the main outcome of interest), beyond the performance of the police. These included larger socio-economic changes occurring within these three provinces as well as the country itself during the five-year implementation period, including infrastructure, education, political economy, among others. Any of these factors could be considered a contributory cause to changes in the outcomes of interest. In addition, SSAPR was not implemented as one intervention uniformly in each of the three sites. Different interventions targeted different actor groups differently in each site, requiring us to further unpack what the "intervention" looked like in each program site.

As such, the $\mathrm{DiD}$ design alone lacked the explanatory power to answer the "hows" and "whys" of program effectiveness as posed in the evaluation questions. We opted, therefore, to nest the DiD design within an overall theorybased design approach as a more appropriate framework for causal inference. Among the different theory-based approaches available, we found CA particularly appropriate for this evaluation, as its original inspiration was as a tool for cases in which multiple factors may have influenced the outcome. CA is particularly recognized for its ability to reduce uncertainty about the contribution of a given intervention to observed results by understanding why the observed results have occurred, highlighting the roles played by the intervention and other internal and external factors. Consequently, the six steps of CA were followed to design and implement the evaluation. The next section describes how the first two steps of CA were conducted to design the evaluation and develop an evaluable ToC for the program using nested actor-based ToCs. The following section outlines how the evaluation was implemented using these actor-based ToCs (steps 3-6 of CA).

The intention of these sections is not to explain how we conducted each step of CA in detail as part of this evaluation. The full SSAPR impact evaluation report, including this methodology, is referenced for the interested reader, along with a number of other articles in the background section that provide a more comprehensive description of how to conduct each step of CA. Rather, this section focuses on how we integrated the use of nested actor-based ToCs into the overall CA exercise. 


\section{Developing an evaluable ToC as part of evaluation design: Steps 1 and 2 of CA}

After identifying the specific cause-and-effect issues to be addressed through agreeing answerable evaluation questions with stakeholders, it was necessary to develop the postulated theory of change for the intervention. As discussed above, developing an evaluable ToC-Step 2 of $\mathrm{CA}-$ is a critical but often neglected component of conducting a robust CA. This can be challenging, however, when program stakeholders have previously developed their own ToC, which can have different aims than evaluation. In these cases it is necessary to develop a more "evaluable" program ToC while not reducing ownership of program stakeholders in the process, since getting their buy-in to the ToC is a necessary first step to obtaining their buy-in for the overall evaluation. This was the situation during the early stages of the SSAPR impact evaluation.

Program stakeholders drafted their first ToC around the mid-point of program implementation, about two years before the evaluation began (Figure 1). The ToC development process therefore employed largely inductive approaches, involving extensive consultations with program stakeholders and based on SSAPR's implementation experience since program start-up.

At the outset of the evaluation, an evaluability assessment of this ToC was conducted. Although there are a number of definitions and interpretations of what makes a ToC "evaluable," the nine criteria that Davies (2013) poses for assessing the evaluability of a program ToC served as pragmatic and useful guidance: clarity, relevance, plausibility, validity or reliability, testability, contextualized, consistent, complexity, and agreement. These criteria help one to assess the degree to which a ToC is clear and plausible and whether relevant data are available for evaluative purposes.

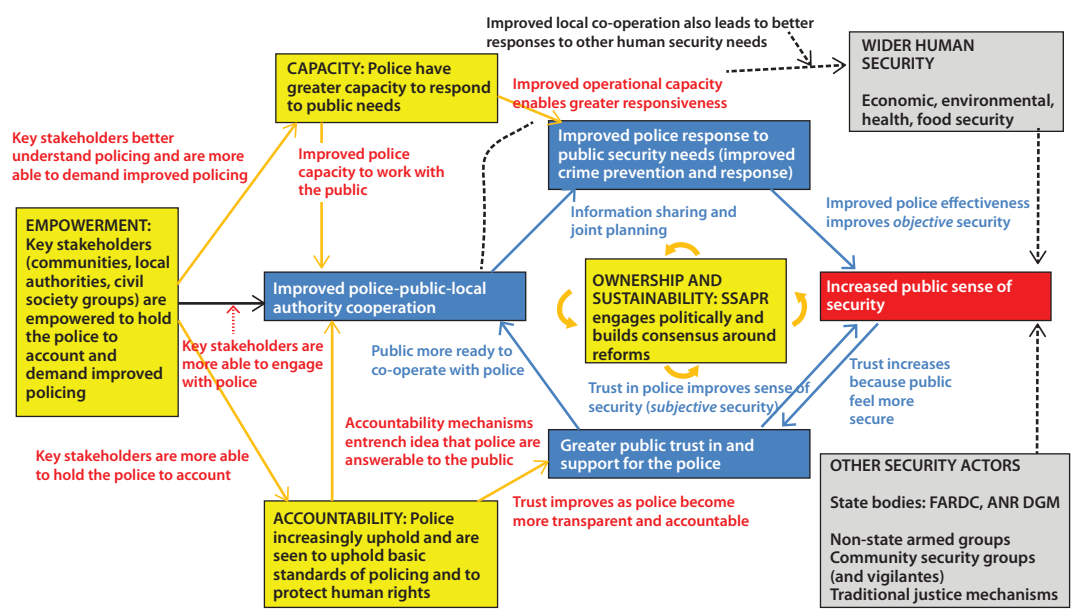

Figure 1: Original program theory of change 
The assessment found that many of the elements of an "evaluable ToC" were sufficiently covered in the program ToC, particularly concerning its clarity, relevance, and plausibility. It also highlighted a number of elements of the ToC that would need to be strengthened in order to use it for evaluative purposes, for instance the testability of some of the causal linkages within the logic and its integration of the more complex aspects of the program, particularly with respect to the expected multiple interactions of different actor groups within the three pilot cities.

This section first describes how the original program ToC was used to develop a more evaluable ToC by adopting an actor-based approach. This is followed by a discussion of how buy-in to these actor-based ToCs (and hence the evaluation design more generally) was gained by working closely with program stakeholders.

\section{An actor-based approach to unpacking a complex ToC}

Based on the results of this assessment, it was determined that some aspects of the ToC would need to be revised to render it more "evaluable." The initial focus was on one of the key assessment findings, which suggested a need to better articulate the expected multiple interactions between program components within the program sites. As each component was designed to target different Congolese actors, the evaluation team first identified the key actor groups involved with each component at the community level. To achieve this, the core program components and activities were first mapped out. Then, for each activity, the target actor group for this activity was identified. An excerpt from the results of this mapping are presented in Table 1.

This mapping exercise identified three key actor groups at the community level directly targeted by SSAPR activities: (i) the police (PNC), (ii) community members, and (iii) local authorities. For each of these three main actor groups, an actor-based ToC was built to outline the pathway for each actor group from SSAPR intervention to the intended program impact. The "useful ToC model" (Mayne, 2015) was adopted as an overall framework for this work.

In this model, activities and results are depicted according to different levels within a program impact pathway as a sequence of results leading from programlevel activities to the long-term intended impact of the program on the identified target population. These include the following levels: activities undertaken by the program; goods and services produced as direct outputs of these activities; the reach of these activities on the intended target groups and the target group's reaction; changes in capacity (knowledge, attitudes, skills, etc.) of those reached by the program's goods and services; the behavioural changes, or changes in practice, that occur among a target group reached; the direct benefits, or improvements, in the state of individual beneficiaries; and the well-being changes, or the longerterm improvements, in the overall lives of individuals.

The useful ToC model also includes external influences, events, and conditions unrelated to the intervention that could contribute to the realization of the intended result, as well as the positive or negative unintended effects that occur as a result of the program's activities and results. Lastly, and importantly, the useful 
Table 1: SSAPR components and activities mapped to key actor groups

\begin{tabular}{|c|c|c|}
\hline $\begin{array}{l}\text { SSAPR } \\
\text { component }\end{array}$ & Activities & Actor groups \\
\hline \multicolumn{3}{|c|}{ PNC capacity: PNC has the capacity to be responsive to local security needs } \\
\hline $\begin{array}{l}\text { Mechanisms to } \\
\text { address public } \\
\text { needs }\end{array}$ & $\begin{array}{l}\text { - Police-community forums } \\
\text { - Training police in community } \\
\text { engagement } \\
\text { - Work with local authorities }\end{array}$ & $\begin{array}{l}\text { - } \quad \text { Local police } \\
\text { - } \quad \text { Community members } \\
\text { - } \quad \text { Local authorities }\end{array}$ \\
\hline \multirow[t]{3}{*}{$\begin{array}{l}\text { Enabling legal } \\
\text { and policy } \\
\text { framework }\end{array}$} & $\begin{array}{l}\text { Technical support to drafting } \\
\text { new legislation, policies, and } \\
\text { operational guidance }\end{array}$ & $\begin{array}{ll}\text { - } & \text { Members of Parliament } \\
\text { - } & \text { Regional delegations } \\
\text { - } & \text { National Police }\end{array}$ \\
\hline & $\begin{array}{l}\text { - Political engagement to ensure } \\
\text { this is adopted }\end{array}$ & - Ministry of Security \\
\hline & - Capacity building of MISDAC & - Ministry of Interior \\
\hline \multicolumn{3}{|c|}{$\begin{array}{l}\text { Empowerment: Key stakeholders can demand improved policing and can } \\
\text { hold the police to account }\end{array}$} \\
\hline \multirow[t]{2}{*}{$\begin{array}{l}\text { Community } \\
\text { engagement }\end{array}$} & $\begin{array}{l}\text { Preparing the public to engage } \\
\text { with police }\end{array}$ & - Community members \\
\hline & - Community scorecards & \\
\hline \multirow{3}{*}{$\begin{array}{l}\text { Capacity of } \\
\text { non-state } \\
\text { actors }\end{array}$} & - Training and support to civil & - Civil society \\
\hline & society, media, and research & - Media \\
\hline & accountability & - Research actors \\
\hline $\begin{array}{l}\text { Discipline and } \\
\text { abuse of power }\end{array}$ & $\begin{array}{l}\text { IG (Inspecteur Général); police } \\
\text { complaints mechanism }\end{array}$ & - National Police / IG \\
\hline \multicolumn{3}{|c|}{$\begin{array}{l}\text { Accountability: The PNC is internally and externally accountable for its } \\
\text { actions }\end{array}$} \\
\hline \multirow{3}{*}{$\begin{array}{l}\text { Building con- } \\
\text { sensus around } \\
\text { reforms }\end{array}$} & $\begin{array}{l}\text { - Daily engagement across state } \\
\text { institutions }\end{array}$ & $\begin{array}{ll}\text { - } & \text { State institutions } \\
\text { - } & \text { Members of Parliament }\end{array}$ \\
\hline & - Building external demand & - Civil society \\
\hline & $\begin{array}{l}\text { - Engagement at both national } \\
\text { and regional levels }\end{array}$ & - Media \\
\hline
\end{tabular}

ToC model includes assumptions about the causal links in the impact pathway: the salient events and conditions that have to occur for each link in the causal pathway to work as expected. Within the model, the arrows between boxes represent expected "causal links" (e.g., that changes in police knowledge and skills lead to changes in police practice), while the "causal link assumptions" explain how and why the causal link is expected to work.

In practice, the information from the original program $\mathrm{ToC}$ and other relevant documents was first mapped onto the useful ToC model for each of the three actor groups. For instance, the different activities targeting the police, the 


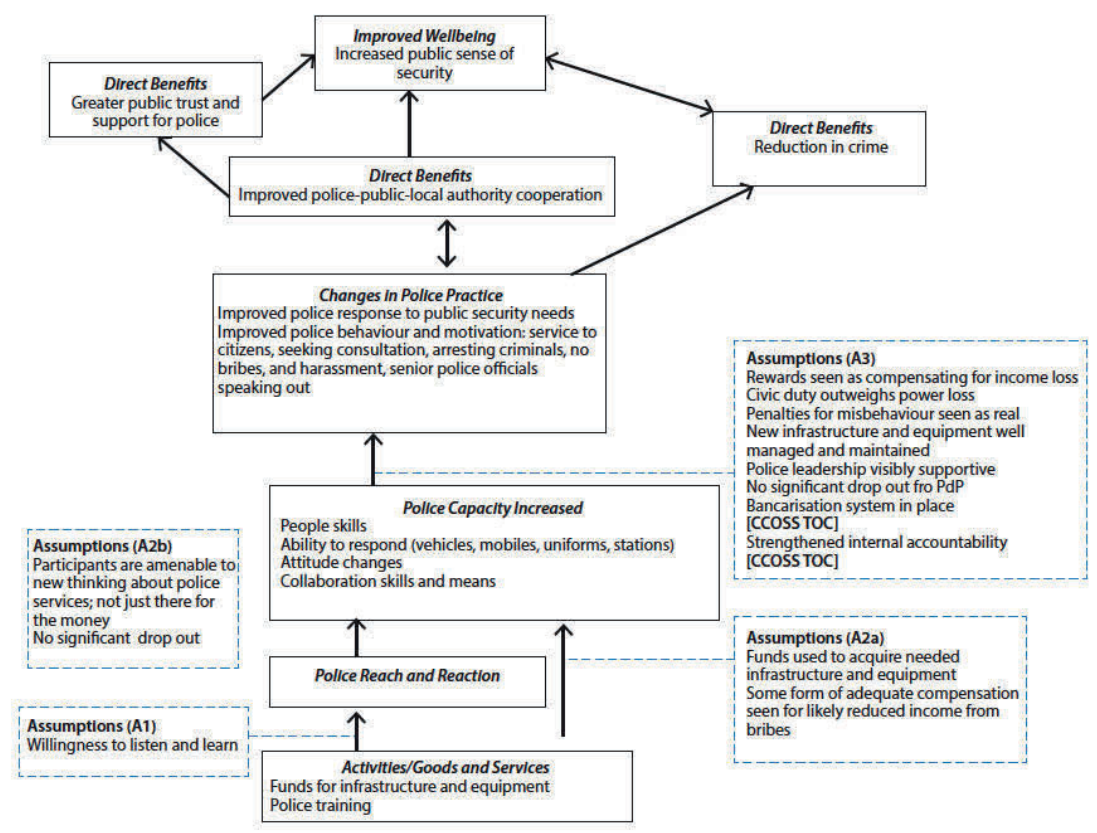

Figure 2: Actor-based theory of change for local police

expected changes in capacity these activities were intended to bring about, and so on, were all mapped to the useful ToC model. Assumptions for each link in the impact pathway were then identified by arguing through the question of what salient events and conditions would need to occur for this pathway to hold true. These initial ToCs were discussed internally within the evaluation team over a series of iterative sessions, engaging both in discussion and consulting (and re-consulting) program documents. This process was particularly useful in articulating the assumptions at each link. An example of the initial actor-based ToC for the local police is included in Figure 2.

The key assumptions included in the three actor-based ToCs largely concerned the ability of and motivation for these key actors to initially change practice, and the conditions that would need to exist to sustain these changes (e.g., changes in incentive structures for the police). Using these assumptions, a second round of actor mapping was then conducted, identifying additional actor groups who were most related to these key causal link assumptions holding true.

For instance, in Figure 2 displaying the police impact story, Assumption box A3 includes an assumption around "strengthened internal accountability mechanisms existing within the police" as a causal link assumption that must hold true for "improved police capacity" to lead to "changes in police practice." Establishing internal accountability mechanisms for the police required a change in practice that the program aimed to bring about through intervention with the Security 


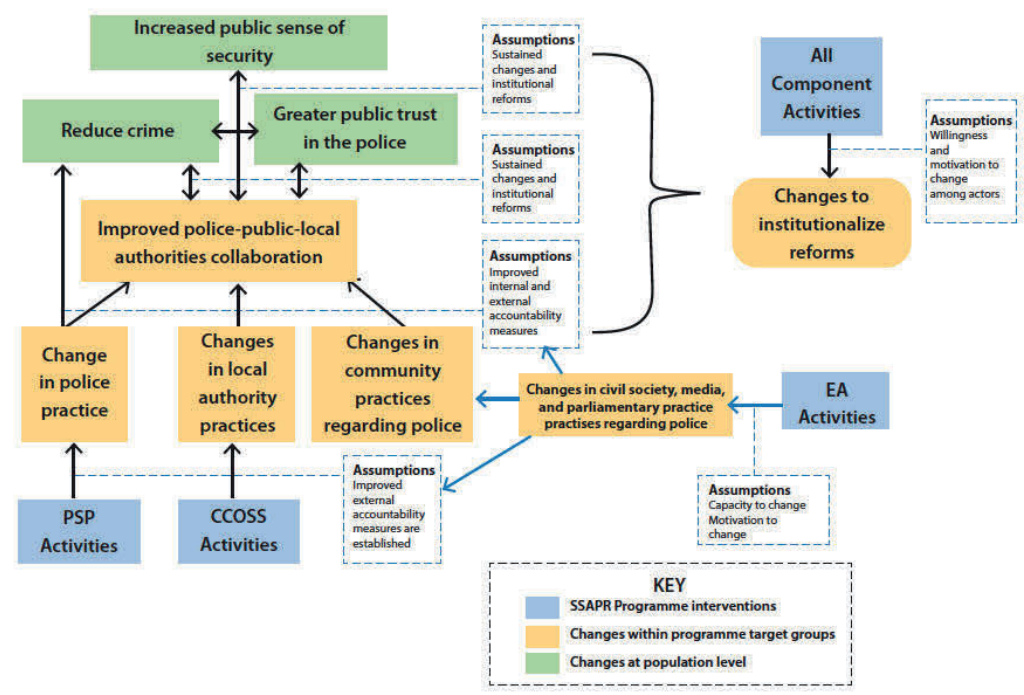

Figure 3: SSAPR actor-based theory of change

Sector Coordination Committee (CCOSS), including the National Police, the Ministry of Interior, and other actors at the national level. A number of secondary actors critical to these assumptions being met were thus identified. Additional nested actor-based ToCs were then built for each of these actors following the same process outlined above: civil society organizations, security sector coordination actors, the media, and parliamentarians within Provincial Assemblies. The different nested actor-based ToCs were then linked into an overview ToC articulating the overall impact pathway and key assumptions required for this impact pathway to hold true (i.e., for SSAPR component activities to cause an increased public sense of security). This is presented in Figure 3. This model then served as the overall ToC used to conduct the rest of the CA exercise.

\section{Getting buy-in from program stakeholders on the evaluable ToC}

The evaluable overview ToC displayed in Figure 3 is visually quite different from the program $\mathrm{ToC}$ developed by program stakeholders displayed in Figure 1. In order for the program stakeholders to buy into our overall evaluation design using $\mathrm{CA}$, it was necessary for them to first have ownership over this revised program ToC, as the actor-based ToCs effectively became the frames of the impact stories where we presented overall evaluation findings.

This was achieved through a number of stakeholder consultations, beginning with a workshop with the evaluation commissioners and program implementers to present the overall evaluation design using CA and discuss the importance of developing an evaluable $\mathrm{ToC}$ as part of this approach. This was 
an important framing exercise to build a shared understanding that a complex intervention such as SSAPR can be depicted through many different models, with each model serving a specific purpose. For example, the original program ToC was built around the Capability, Accountability and Responsiveness (CAR) model of understanding governance, as program stakeholders felt it was important to capture both the operational aspects of the program's interventions to strengthen police capacity as well as the focus on improving police governance around a democratic policing model (Moore \& Teskey, 2006). The ToC also explained the program in the context of larger security-sector reform occurring in the DRC. At the time, this was a key program tool in driving more integrated program delivery at the site level, as opposed to the fragmented and "siloed" delivery by program components that had characterized the initial years of program intervention.

This provided an entry point to discuss some of the limitations of the program ToC from an evaluability perspective in a way that did not discredit the importance of the original model for the purposes of more integrated delivery and shifting the thinking of implementers from a focus on police capacity to a broader perspective of police governance. From this common understanding, a number of one-on-one consultations with each program component were then organized to explain the approach to developing actor-based nested ToCs based on the original program ToC model in order to strengthen the causal logic within the original ToC and clarify the multiple interactions occurring at a site level. This was done by replicating the actor-based mapping exercise for each program component's activities in a collaborative session. This was a very practical and hands-on exercise that participants found easy to engage in and stimulated good discussion around who the program is targeting and how, as well as differences in implementation in the three different program sites.

The overall useful ToC model was then presented as a framing concept to understand more generally "how change happens" among actor groups. In comparison to using evaluation jargon around outputs, outcomes, and impacts, program stakeholders were able to relate to and more easily grasp the steps in the useful ToC causal model. For instance, program implementers could more easily discuss what changes in practice they wished to see in the different actor groups targeted and describe in their own words how they thought their program activities would lead to these changes in practice (e.g., building capacity through skills training).

This not only led to a more meaningful conversation about the initial impact pathway for each actor group, which generated useful additions and clarifications to our initial logic, but also provided an opportunity to pose a number of questions that challenged program stakeholders' logic and thus identified additional assumptions for inclusion in the nested actor-based ToC models. It also resulted in program implementers identifying a number of relevant program documents that could then be used in evaluation implementation. The next section discusses how these actor-based ToCs were then used to implement the evaluation and generate evaluation findings. 


\section{HOW GOOD ACTOR-BASED TOCS ALLOW FOR GOOD IMPACT STORIES}

The previous section described how the original program ToC, relevant program documents, and a series of stakeholder consultations were used to develop an evaluable ToC for the evaluation (Steps 1 and 2 of CA). In this section, the use of nested actor-based ToCs to construct robust impact stories (Steps 3-6 of CA) is described.

\section{Gathering data for impact stories: Step 3 of $C A$}

Based on this overall ToC model, a set of indicators was first identified that could be used to assess the degree to which each step in the impact pathway held true for each actor group and the degree to which causal link assumptions were met. Existing possible data to report against each indicator were then gathered. This included a number of data sources produced by the program components, including program monitoring data, quantitative survey data and qualitative research studies. Many of the research studies used as secondary sources were research reports conducted by the Monitoring \& Evaluation (M\&E) component over the life of the project. The remainder of this section provides a short description of the main data sources used. ${ }^{2}$

\section{Household surveys}

A main data source for the evaluation was the results of two cross-sectional representative household sample surveys in three SSAPR pilot sites and three matched comparison sites (three "city pairs"), using a structured questionnaire in 2010 at baseline and in 2014 at endline. Sampling followed a stratified sampling approach, which maximized the likelihood of matching and capturing comparable population samples over time. Over 8,000 individuals were sampled in each round, ensuring equal numbers of men and women. Data were collected using a quantitative questionnaire. Samples were analyzed through a difference-indifference (DiD) approach to produce quantitative estimates of change over time attributable to the program.

\section{Program monitoring data}

All available program monitoring data were also gathered from the program components, including quarterly and annual reports and other thematic reports around specific interventions. After an initial review, the program was requested to provide additional data sources as well, which were highlighted in the initial reports. In total, the evaluation team reviewed and analyzed over 100 independent data sources from the program's routine monitoring system.

\section{ToC monitoring}

ToC monitoring is a longitudinal research approach we adapted from the outcome mapping methodology, which allowed the research team to consider how SSAPR and other actors may have contributed to change, as a diverse range of actors influenced each change as part of complex, long-term processes. This study was 
conducted during the last year of program implementation and involved conducting retrospective community scorecards and focus-group discussions (FGDs) during repeated visits to SSAPR intervention and comparison sites.

\section{Thematic research studies}

Two thematic research studies conducted by the M\&E component were also drawn from for this. The first was a Rapid Assessment, Response and Evaluation study, conducted in 2013, which aimed to explore the link between the security and justice sectors in the DRC from both the supply and the demand sides. The second was a study on the state of gender mainstreaming as part of the process of reform in the PNC.

\section{Assembling and revising impact stories: Steps 4-6 of CA}

Following Step 4 of the CA approach, the nested actor-based ToCs were then used as the structure for constructing impact stories. For each actor-based ToC, all relevant data from the data sources gathered were systematically extracted and organized against each indicator. The evidence extracted for each indicator was then synthesized and assessed in terms of the strength of available evidence to support that each change occurred or causal link assumption was realized, using the following rating scale:

- $\quad$ GREEN indicated evidence was available confirming that a change occurred or an assumption was fully realized;

- $\quad$ AMBER indicated mixed evidence for/against a change occurring or an assumption being realized;

- $\quad \underline{R E D}$ indicated evidence available disproving a change or that an assumption was not realized; and

- $\quad$ BLUE indicated that no/little evidence was available, so no conclusions could be drawn.

This was further distilled into a complex narrative of change, or impact story, structured along the causal impact pathway and presenting the multi-source evidence that supported causal and contributory claims. A separate impact story was developed for the three primary actor groups. An impact story around the Overview ToC was also developed to investigate the impact of the program on perceptions of public security. The four impact stories created are displayed in Figure 4. Each actor-based impact story also included an assessment of sustainability at the assumption level. Here, evidence was analyzed and presented on the degree to which the change occurred during the program implementing period, and the degree to which emerging evidence suggested that this change would be sustained after the program ended.

Following Steps 5 and 6 of CA, impact stories were presented to program stakeholders in a participatory workshop in order to identify data gaps that could be filled by both program monitoring data and additional primary data collection. Based on initial stakeholder consultations, the evaluation team then sought 


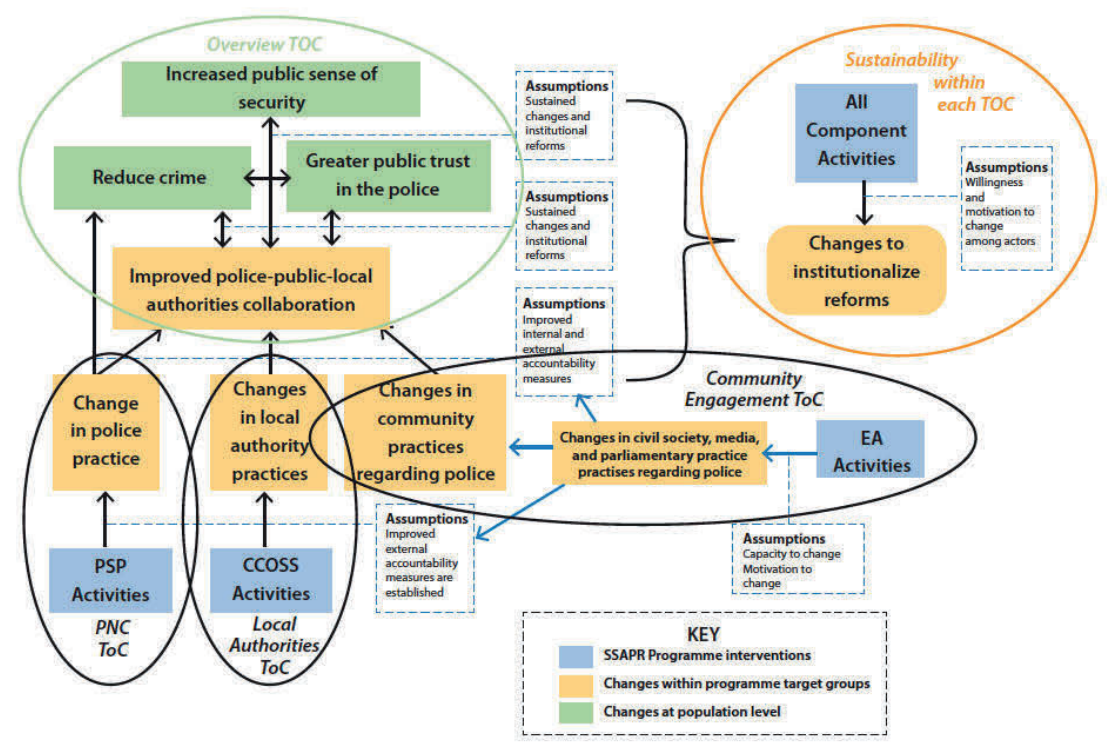

Figure 4: Nested actor-based impact stories

to fill any evidence gaps through additional primary data-collection exercises. The major evidence gaps identified were around the potential contribution of other external or influencing factors on study results. To fill these gaps, a number of focus-group discussions and key informant interviews with representatives of groups not previously targeted for in-depth qualitative research were conducted. It also identified a number of secondary data sources that could help to fill data gaps. The data from these additional data-gathering exercises were extracted and added to the indicator-synthesis exercise, strength-of-evidence assessment, and ultimately each impact story.

The outcome was a revised and final set of impact stories. The findings from this last step were shared with program stakeholders. Both internal and external stakeholders, including independent quality-assurance reviewers with backgrounds in evaluation methods and security and justice programs in developing country settings, provided a subsequent round of comments. The results of these reviews were further incorporated into the impact stories.

\section{EXAMPLE OF STUDY FINDINGS}

To provide an illustrative example of what the final product of this analysis looked like, two excerpts are included below from the impact stories of two of the primary actor groups: the police and community members. The actor-based ToCs and impact story for all actor groups are available in the full evaluation report (Palladium, 2016). Each impact story begins with a diagrammatic nested actor-based ToC outlining the main impact pathway and causal assumptions. Within these 
diagrams the colours used above to represent the strength of available evidence are also used.

\section{Police impact story: Police officers exposed to SSAPR have positively changed their practice as a result of SSAPR intervention}

The police component of the program aimed to improve police practice to better serve the public and respond to community needs by training the police and providing infrastructure and equipment support. SSAPR reached a sufficient number of police officers with police support interventions in favour of the community policing model, or police de proximité ( $\mathrm{PdP})$, including intensive training and coaching for over 1,500 officers. For some police officers, this was the first training they had received.

Several gender-targeted activities were also conducted, initially in support of victims of gender-based violence (GBV). Police stations were provided with infrastructure and equipment to support the police in dealing with female victims and cases of GBV. The program also incorporated training into the community policing approach on how to effectively deal with cases of GBV. Additional gender mainstreaming and gender-equity activities began relatively late in the program. This included integrating gender focal points into police operations and developing strategies to mainstream gender issues across the organization.

Community members also reported improvements in police practice over time in SSAPR pilot sites, specifically among officers trained by the program in community policing. Quantitative analysis indicated that positive interactions

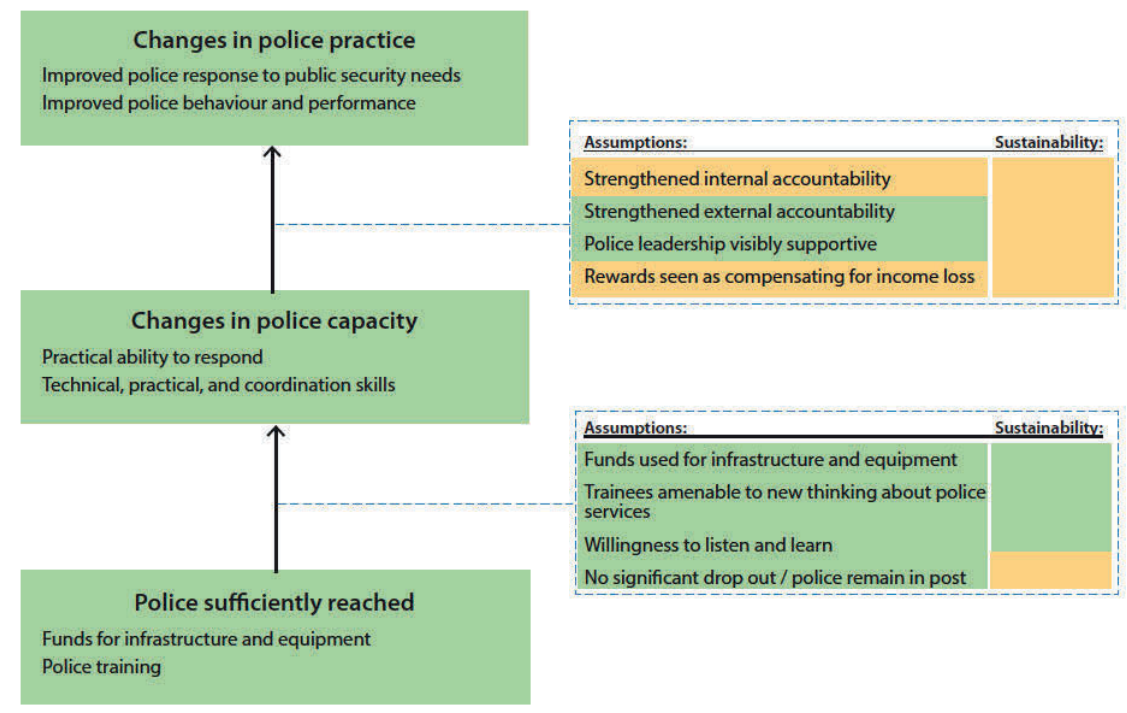

Figure 5: Actor-based theory of change for police 
with a community police officer were highly correlated with improved perceptions of security. Community members in SSAPR pilot sites also reported seeing more frequent patrols over the life of the program. To support these changes, the program supported the media and civil society in establishing external accountability mechanisms in SSAPR pilot sites to hold the police to account for their behaviour.

The volume of evidence gathered during this evaluation suggested that these changes were credibly the result of SSAPR activities. Participation in the police training program improved the capacity of the police and their practices, although work here may be beginning to slip, with declining police motivation and a reduction in activity within external accountability mechanisms. The evidence is more mixed on the degree to which changes in equipment and infrastructure supported by the program led to changes in police practice, although it seems to have had an effect on the community's perceptions of the police's capacity. Supplementary analysis also did not find evidence of any compelling external factors likely to have strongly influenced these changes, strengthening the certainty of our findings.

\section{Community-member impact story: Communities in SSAPR pilot sites have positively changed their practice around community engagement as a result of SSAPR}

The evaluation found community-engagement activities organized through community-group actors-namely, civil society organizations (CSOs) and the media-were successful in reaching a large proportion of the population with education and awareness-raising activities. Evaluation findings indicated that changes in CSO and media practice were effective in providing opportunities

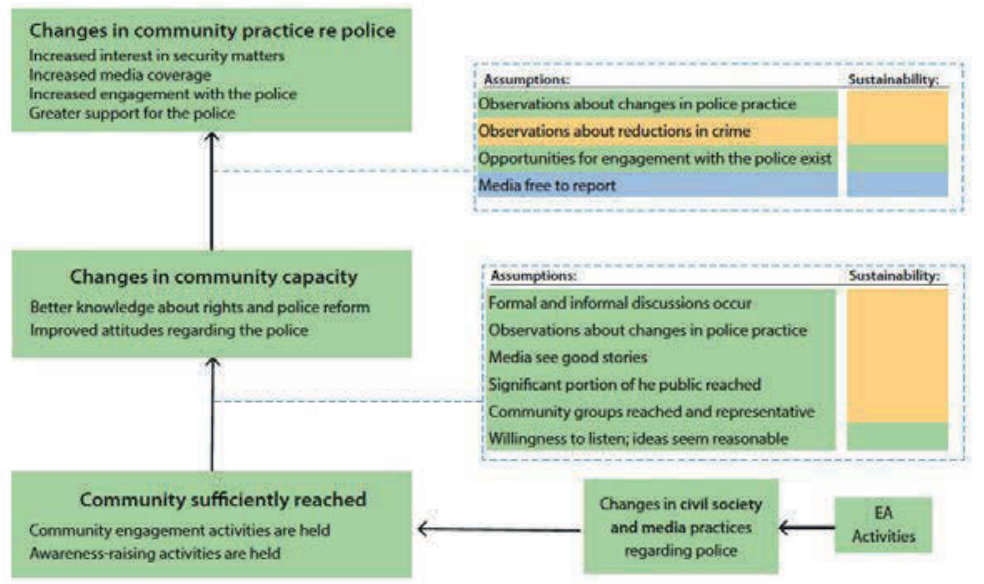

Figure 6: Actor-based theory of change for community members 
for engagement with the police, through community fora (known as forums de quartier) and other community-engagement events.

This led to changes in community practice regarding engagement with the police. More than one-third of respondents in household surveys in SSAPR intervention sites reported having participated in a community forum or other community-engagement event. Qualitative data gathered during this evaluation suggested that both the police and community members attended and actively participated in these fora and events.

Given the large reach of these activities, and because no other security-related education or awareness campaigns occurred in SSAPR sites during the implementation period, it is reasonable to conclude that exposure to SSAPR-initiated activities led to this change in community capacity. As community-engagement activities were ongoing and able to sustain a high degree of interest and positive engagement from pilot communities over a number of years, the evaluation team concluded that changes in community capacity and practice with regard to the police were indeed the result of exposure to SSAPR community-engagement activities. Analysis also did not find any compelling evidence of external factors that could have strongly influenced these changes, strengthening the certainty of our findings.

This sustained change in community practice, however, is predicated on other actors, such as CSOs, the media, and local authorities continuing to provide engagement opportunities for community members to use their improved capacity to better engage with the police. Although these opportunities existed over the life of the program, they were all funded, and in some cases coordinated, by SSAPR. Emerging evidence indicates that some of these activities may be beginning to decline in the absence of funding from the intervention.

\section{CONCLUSION}

\section{Strengths and weaknesses of the evaluation approach}

Overall, this experience using nested actor-based ToCs to evaluate complicated and complex aspects of an intervention through CA identified a number of strengths and weaknesses. There are a number of benefits:

Unpacking complexity. The focus on actors was a useful way of understanding causality in a complex program such as SSAPR, with multiple component activities working with multiple target populations to bring about long-term and sustained change in the population at large. Identifying who was being targeted by which interventions, and how they were connected, helped to better articulate the causal logic and identify packages of interventions targeting specific stakeholder groups. Equally, linking causal-link assumptions between the different actor-based ToCs provided a robust picture of who needed to change (and how) in order to bring about the program's intended results. This was important in engaging with program teams on what could realistically be expected to change, and in what timeframe. 
Engaging with stakeholders. The ability to engage program stakeholders into the actor-based approach was also a significant advantage. Stakeholders were better able to articulate and reflect on changes when put in the context of specific actor groups as opposed to more theoretical causal-impact pathways that are often used in theory-based approaches. This allowed for meaningful and constructive critique of initial draft impact stories and the identification of how the impact stories-and thus the contribution claims within the evaluation-could also be strengthened.

Constructing impact stories. The nested actor-based ToCs also provided a pragmatic framework for organizing a wealth of information within each impact story. As hundreds of primary and secondary sources were analyzed to extract data for the impact stories, the actor-based focus helped us in coding and organizing large amounts of data.

Assessing sustainability. This actor-based approach also helped to usefully build in an assessment of the likelihood of sustainability of the intervention. By focusing on how actors would need to sustain a behavioural change, it was possible to assess factors that would need to remain in order to create these favourable conditions and better determine which were likely to remain in the absence of program funds. Although many impact evaluations include "sustainability" as a key measure, it is often difficult in real terms to incorporate this into an evaluation design. The focus on actor-level sustainable behaviour change was a pragmatic way to address this critical component of impact evaluation.

Despite these advantages, some challenges are also useful to reflect on for future applications of nested actor-based ToC approaches:

Selecting impact stories. There were some initial difficulties in situating the focus of the impact stories. With six research sites and four impact stories in each site, it was not feasible to conduct over twenty individual impact stories or a higher-level synthesis, due to time and financial constraints. Therefore, it was necessary to decide early on how to best structure the impact stories. It was decided in the end to conduct one overarching impact story for each actor group and include "variations to the narrative" to report variation observed across actor groups and different sites.

Significant time commitment. The development of these iterative impact stories did require a substantial time commitment from evaluation stakeholders, particularly the program teams. This was challenging, given that the program was shutting down and program staff were consequently under immense time pressure; however, their participation in the process was considered critical to the success of the approach. In the future, a realistic assessment of time commitments should be made and discussions held up front with program teams to manage expectations.

Significant data requirements. Last, it should be noted that developing ToCs for each actor group-both the primary and secondary actor groupsrequired a significant amount of data. But there is a positive correlation between the amount of data used to construct impact stories and the strength of the contributory claims that can be made within each actor-based impact story. Both the 
availability of data and the time required to gather and analyze them are important factors to be considered.

\section{Future improvements}

We continue to use actor-based ToCs in our evaluation work and have built in several enhancements since conducting this evaluation. As modelling behaviour change is the basis for these ToCs, we now see a stronger and more intuitive behaviour-change model, namely the COM-B model developed by Michie, van Stralen, and West (2011), whereby behaviour (B) occurs as the result of interaction between three necessary conditions: capabilities $(\mathrm{C})$, opportunities $(\mathrm{O})$, and motivation (M). For instance, in constructing the actor-based ToCs for each actor group as part of this evaluation, we found the "capacity" box within the useful ToC model to be particularly difficult to fully articulate and explain for each actor group, as different stakeholders had a different understanding of what "capacity" was-often limited to a technocratic perspective (e.g., knowledge and skills) — and we found that it did not fully capture constructs such as "attitudes" and "motivations" to change practice. Applying the COM-B framework more clearly identifies the conditions needed to bring about behaviour change. The COM-B ToC model is discussed by Mayne (2018b).

Indeed, we have found that articulating the COM-B construct for each actor group can strengthen the causal logic within an actor-based $\mathrm{ToC}$ and more robustly identify causal-link assumptions. For example, by fully identifying the different conditions associated with a behaviour, it is possible to identify both an actor's current capabilities, opportunities, and motivations (which explain their current behaviour) and how these conditions would need to change to stimulate the expected behavioural change. This allows one to better identify two sets of changes: the changes in behavioural conditions that are targeted by program intervention(s) and thus expected to change due to program intervention, strengthening the primary impact pathway of the actor-based $\mathrm{ToC}$; and those that are not specifically targeted by the program but would need to hold true nonetheless for the behavioural change to occur, strengthening the causal-link assumptions in the actor-based ToC. This can serve as the basis for articulating an evaluable actor-based program theory useful for program design as well as evaluation. This is further discussed in Koleros, Mulkerne, Oldenbeuving, and Stein (2018).

One of the key challenges in developing ToCs is identifying the assumptions for each causal link in the ToC. This was certainly the case in the SSAPR evaluation. More recently, Mayne has also developed further guidance on articulating assumptions. In Mayne (2018b), generic criteria for the COM-B model are discussed. Several of the criteria for robust ToCs involve testing the soundness and necessity of assumptions (Mayne, 2017). And in Mayne (2018a), there is a discussion on generating causal link assumptions.

A key message of this article is that CA is only as good as the ToC used. A second improvement in the approach is using more clearly the criteria for a robust 
ToC. Starting with Davies's conditions mentioned above, Mayne (2017) has developed criteria for robust ToCs around two sets of criteria:

- criteria for a structurally sound ToC, and

- criteria for a structurally sound ToC that is plausible.

These criteria provide more structure for developing robust ToCs.

\section{Final remarks}

Our use of actor-based ToCs on this evaluation as well as in other contexts has led us to conclude the following:

- $\quad$ since complex interventions target different actors, building actor-based ToCs is a pragmatic way to unpack the complexity of an intervention;

- $\quad$ adopting an actor-based approach can help to strengthen the evaluability of a ToC, as it ensures that no key causal linkage between actor groups is omitted from the logic and that all actors targeted by an intervention are sufficiently included;

- $\quad$ applying the useful ToC model as part of an actor-based ToC helps to build buy-in of an overall evaluation by relating difficult and complex concepts in easily understood terms, allowing stakeholders to more easily engage in the evaluation process and its findings; and

- telling the story of a complex intervention is not obvious: focusing on the actors involved provides a basis for meaningful stories that stakeholders can relate to, while maintaining the causal logic of the overall ToC.

It is hoped that sharing this experience will contribute to the use of actor-based ToCs as a way to develop robust ToCs both for effective applications of CA and other similar approaches.

\section{NOTES}

1. CA does not rely on opinions about the contribution being made, as some have suggested (Schmitt \& Krisch, 2017), but rather on empirically verifying a theory of change.

2. A more detailed data-collection method for each of these data sources, including the sampling strategy for the household survey mentioned below, is included in the full impact evaluation report.

\section{REFERENCES}

Befani, B., Barnett, C. \& Stern, E. (2014). Introduction: Rethinking impact evaluation for development. IDS Bulletin, 46(6), 1-5. http://doi.org/10.1111/1759-5436.12108

Buckley, A. P. (2016). Using Contribution Analysis to evaluate small \& medium enterprise support policy. Evaluation, 22(2), 129-148. https://doi.org/10.1177/1356389016638625 
Buregeya, J. M., Brousselle, A., Nour, K., \& Loignon, C. (2017). Comment évaluer les effets des évaluations d'impact sur la santé : le potentiel de l'analyse de contribution. Canadian Journal of Program Evaluation, 32(1), 25-45. http://doi.org/10.3138/cjpe.31151

Byrne, D. (2013). Evaluating complex social interventions in a complex world. Evaluation, 19(3), 217-228. https://doi.org/10.1177/1356389013495617

Copestake, J. (2014). Credible impact evaluation in complex contexts: Confirmatory and exploratory approaches. Evaluation, 20(4), 412-427. https://doi. org/10.1177/1356389014550559

Davies, R. (2013). Planning evaluability assessments: A synthesis of the literature with recommendations. Working Paper 40: DFID. Retrieved from https://www.gov.uk/ government/uploads/system/uploads/attachment_data/file/248656/wp40-planningeval-assessments.pdf

Delahais, T., \& Toulemonde, J. (2017). Making rigorous causal claims in a real-life context: Has research contributed to sustainable forest management? Evaluation, 23(4), 370-388. https://doi.org/10.1177/1356389017733211

Downes, A., Novicki, E., \& Howard, J. (2018). Using the contribution analysis approach to evaluate science impact: A case study of the National Institute for Occupational Safety and Health. American Journal of Evaluation. Advance online publication. https://doi. org/10.1177/1098214018767046

Funnell, S. C., \& Rogers, P. J. (2011). Purposeful program theory. San Francisco, CA: JosseyBass.

Garcia, J. R. \& Zazueta, A. (2015). Going beyond mixed methods to mixed approaches: A systems perspective for asking the right questions. IDS Bulletin, 46(1), 30-43. https:// doi.org/10.1111/1759-5436.12119.

Gerrits, L. \& Verweij, S. (2015). Taking stock of complexity in evaluation: A discussion of three recent publications. Evaluation, 21(4), 481-491. https://doi. org/10.1177/1356389015605204

James, C. (2011). Theory of change review: A report commissioned by Comic Relief. Comic Relief. Retrieved from http://www.actknowledge.org/resources/documents/James_ ToC.pdf

Kane, R., Levine, C., Orians, C., \& Reinelt, C. (2017). Contribution analysis in policy work: Assessing advocacy's influence. Centre for Evaluation Innovation. Retrieved from http://www.evaluationinnovation.org/sites/default/files/Contribution Analysis_0.pdf

Koleros, A., Mulkerne, S., Oldenbeuving, M., \& Stein, D. (2018). The actor-based change $(\mathrm{ABC})$ framework: A pragmatic approach to program theory in complex systems. American Journal of Evaluation, advance online publication. http://www.doi. org/10.1177/1098214018786462

Mayne, J. (2001). Addressing attribution through contribution analysis: Using performance measures sensibly. Canadian Journal of Program Evaluation, 16(1), 1-24. Retrieved from https://pdfs.semanticscholar.org/7501/501b7fb4ee9f31985540f3e1ca661f262 ec6.pdf

Mayne, J. (2009). Building an evaluative culture in organizations: The key to effective evaluation and results management. Canadian Journal of Program Evaluation, 24(2), 1-30. Retrieved from https://evaluationcanada.ca/secure/24-2-001.pdf 
Mayne, J. (2011). Contribution analysis: Addressing cause and effect. In R. Schwartz, K. Forss, \& M. Marra (Eds.), Evaluating the complex (pp. 53-96). New Brunswick, NJ: Transaction.

Mayne, J. (2012a). Contribution analysis: Coming of age? Evaluation, 18(3), 270-280. https://doi.org/10.1177/1356389012451663

Mayne, J. (Ed.). (2012b). Special issue: Contribution analysis. Evaluation, 18(3).

Mayne, J. (2015). Useful theory of change models. Canadian Journal of Program Evaluation, 30(2), 119-142. Retrieved from https://evaluationcanada.ca/system/files/cjpeentries/30-2-119_0.pdf

Mayne, J. (2017). Theory of change analysis: Building robust theories of change. Canadian Journal of Program Evaluation, 32(2), 155-173.

Mayne, J. (2018a). Developing and using useful theories of change. Evergreen briefing note. Retrieved from https://www.researchgate.net/publication/323868372_Developing and_Using_Useful_ToCs

Mayne, J. (2018b). The COM-B theory of change model: Working paper. Retrieved from https://www.researchgate.net/publication/323868561_The_COMB_ToC_Model4.

Mayne, J. (Forthcoming). Realistic commissioning of impact evaluations: Getting what you ask for? In A. Paulson \& M. Palenberg (Eds.), Evaluation and the pursuit of impact. Taylor and Francis.

Mayne, J., \& Johnson, N. (2015). Using theories of change in the CGIAR research program on agriculture for nutrition and health. Evaluation, 21(4), 407-428. https://doi. org/10.1177/1356389015605198

Michie, S., van Stralen, M. M., \& West, R. (2011). The behaviour change wheel: A new method for characterising and designing behaviour change interventions. Implementation Science, 6(42), 11. https://doi.org/10.1186/1748-5908-6-42

Moore, M. and Teskey, G. (2006) The CAR framework: Capability, accountability, responsiveness. What do these mean, individually and collectively? Discussion note for DFID governance and conflict advisers. Retrieved from http://www2.ids.ac.uk/gdr/ cfs/pdfs/CARframeworkDRCweb.pdf

Noltze, M., Gaisbauer, F., Schwedersky, T., \& Krapp, S. (2014). Contribution analysis as an evaluation strategy in the context of a sector-wide approach: Performance-based health financing in Rwanda. African Evaluation Journal, 2(1). https://doi.org/10.4102/ aej.v2i1.81

Palladium. (2016). Independent evaluation of the Security Sector Accountability and Police Reform Programme. Retrieved from https://assets.publishing.service.gov.uk/ government/uploads/system/uploads/attachment_data/file/563343/Eval-securitysector-accountability-police-reform-prog.pdf

Ramalingam, B. (2013). Aid on the edge of chaos: Rethinking international cooperation in a complex world. Oxford, England: Oxford University Press.

Ramalingam, B., \& Jones, H. (2008). Exploring the science of complexity: Ideas and implications for development and humanitarian efforts. Working Paper 285. London, UK: Overseas Development Institute. Retrieved from https://www.odi.org/sites/odi.org. uk/files/odi-assets/publications-opinion-files/833.pdf 
Rogers, P. (2008). Using programme theory to evaluate complicated and complex aspects of interventions. Evaluation, 14(1), 29-48. http://dx.doi.org/10.1177/1356389007084674.

Schmitt, J., \& Krisch, F. (2017). A mechanism-centered approach to evaluating complex aid interventions: The case of accompanying measures to budget support. Journal of MultiDisciplinary Evaluation, 13(28). Retrieved from http://journals.sfu.ca/jmde/ index.php/jmde_1/article/view/455

Stein, D., \& Valters, C. (2012). Understanding 'Theory of Change' in international development: A review of existing knowledge. The Asian Institute and the Justice and Security Research Programme. Retrieved from http://www.theoryofchange.org/wp-content/ uploads/toco_library/pdf/UNDERSTANDINGTHEORYOFChangeSteinValtersPN. pdf

Terrapon-Pfaff, J., Gröne, M.-C., Dienst, C., \& Ortiz, W. (2018). Impact pathways of small-scale energy projects in the global south: Findings from a systematic evaluation. Renewable and Sustainable Energy Reviews, 95, 84-94. https://doi.org/10.1016/j. rser.2018.06.045

Ton, G. (2017). Contribution analysis of a Bolivian innovation grant fund: Mixing methods to verify relevance, efficiency and effectiveness. Journal of Development Effectiveness, 9(1), 120-143. http://doi.org/10.1080/19439342.2016.1231702

Valters, C. (2014). Theories of change in international development: Communication, learning, or accountability? JSRP Paper 17: The Asia Foundation. Retrieved from http:// www.lse.ac.uk/internationalDevelopment/research/JSRP/downloads/JSRP17.Valters. pdf

Vogel, I. (2012). Review of the use of 'Theory of Change' in international development. Department for International Development (DFID). Retrieved from http://www. oxfamblogs.org/fp2p/wp-content/uploads/DFID-ToC-Review_VogelV4.pdf

\section{AUTHOR INFORMATION}

Andrew Koleros is a researcher at Mathematica Policy Research. He has over fifteen years of experience in the design and implementation of programme monitoring, evaluation and learning systems for development programmes.

John Mayne is an independent advisor on public sector performance. Over the past 13 years he has focused largely on international development evaluation and results-based management work. 